\title{
Considerations in selecting rapid-onset opioids for the management of breakthrough pain
}

\author{
This article was published in the following Dove Press journal: \\ Journal of Pain Research \\ 5 March 2013 \\ Number of times this article has been viewed
}

\author{
Howard S Smith \\ Departments of Anesthesiology, \\ Medicine, and Physical Medicine and \\ Rehabilitation Albany Medical College, \\ Albany, NY, USA
}

\begin{abstract}
Breakthrough pain (BTP) is a transitory pain that occurs despite the use of longterm, around-the-clock analgesia. It is highly prevalent in certain populations and places a significant burden on patients, their families, caregivers, and health-care systems. Despite its prevalence and impact, BTP is sometimes unrecognized and often undertreated. Various formulations of fentanyl - a rapid-onset opioid with short duration of action - are available for the management of BTP. The efficacy of formulations using transmucosal, transbuccal, sublingual, and intranasal administration routes has been demonstrated for BTP treatment in clinical trials. However, a lack of head-to-head trials evaluating their relative efficacy makes it challenging for physicians to reach informed decisions on the most efficacious intervention for individual patients. In the absence of clear data on the relative efficacy of fentanyl formulations, prescribing decisions need to be based on physician understanding and experience and product cost and availability, taking into account the individual patient's needs, the ability of the patient or caregivers to administer medication, and the patient's wishes. This review evaluates current pharmacologic methods of alleviating BTP and discusses factors that should be considered when selecting the most appropriate formulation for individual patients. With the range of fentanyl formulations available, it is now possible to successfully address BTP in the majority of patients.
\end{abstract}

Keywords: rapid-onset opioid, breakthrough pain, pain, fentanyl

\section{Breakthrough pain}

Breakthrough pain (BTP) is a transitory pain that occurs despite the use of long-term, around-the-clock analgesia to control chronic pain. It is highly prevalent in certain patient populations, including those with chronic cancer pain and those with noncancer pain. ${ }^{1-4}$ BTP may be nociceptive (localized pain due to injury outside the nervous system), neuropathic (pain caused by damage to the central or peripheral nervous system), or both..$^{5}$ It can arise spontaneously, incidentally with physical activity, or when previous pain medication fails. ${ }^{5}$

Although the median duration of BTP is only 30-60 minutes and it is generally self-limiting, BTP is widely recognized as placing a significant burden on patients, their families, caregivers, health-care systems, and society as a whole. ${ }^{6-8}$ For patients with cancer, BTP is associated with decreased functional status and increased levels of anxiety and depression. ${ }^{4,7}$ In addition, patients with BTP express greater dissatisfaction with treatment, and treatment is associated with poorer medical outcomes. ${ }^{9,10}$ However, despite its prevalence and impact on patients, BTP is sometimes unrecognized and often undertreated. Reasons underlying this may include a lack of understanding about
Correspondence: Howard S Smith Department of Anesthesiology, Albany Medical College, 47 New Scotland Avenue, MC 13I Albany, NY 12208, USA Tel + I 5 I8 $262446 \mid$

Fax +I 5182624462

Email smithh@mail.amc.edu 
BTP, low prioritization, and concerns among health-care professionals and patients about overmedicating. ${ }^{11}$

One of the challenges in treating BTP is that pain is an inherently subjective sensation. Parameters such as pain intensity, pain relief, and global medication performance can only be measured using patient-reported assessments, eg, using category scales for pain intensity and pain relief, and visual analog scales. ${ }^{12}$ In order to account for differences in baseline pain intensity between patients, each individual's subsequent pain-intensity category and visual analog scale scores are converted into pain-intensity difference (PID) scores by subtracting them from the pain score reported at baseline. When interpreting clinical trial data using patientreported outcomes for BTP, however, it is important to consider whether changes in these parameters are clinically meaningful rather than just statistically significant.

In an important study conducted by Farrar and colleagues, a PID decrease of at least $33 \%$ from baseline within 30 minutes of administration of oral rapid-onset opioid was validated as a clinically important improvement. ${ }^{12}$ In addition to the improvements in PID, Farrar and colleagues identified clinically meaningful changes as being $\geq 2$-point reductions in absolute pain intensity (on an 11-point numeric scale where $0=$ no pain and $10=$ worst pain imaginable), pain-relief scores of $\geq 2$ (on a 5-point categorical scale where $0=$ no pain relief and $4=$ complete pain relief), and a global medication performance score of $\geq 2$ (on a 5-point categorical scale where $0=$ poor and $4=$ excellent $).{ }^{12}$

The mainstay of BTP treatment has traditionally been immediate-release morphine sulfate and immediate-release oxycodone; however, the pharmacokinetic profiles of these agents do not usually match the dynamics of BTP, in particular the time to peak pain intensity. Although some patients may experience a predictable, gradual onset in BTP that rises to peak intensity over a period of approximately $15-45$ minutes, for the majority of patients, their BTP is unpredictable, rising steeply to peak intensity within about 5-15 minutes. Oral immediate-release morphine sulfate has a time to onset of analgesia of approximately 30 minutes, takes 1.1 hours to achieve maximal plasma concentration $\left(\mathrm{C}_{\max }\right)$, and has a halflife $\left(t_{1 / 2}\right)$ of approximately 2 hours. In addition, dosing of oral morphine is hampered by extensive first-pass metabolism and poor bioavailability $(20 \%-40 \%) .{ }^{13-16}$ Similarly, immediaterelease oxycodone has a time to onset of analgesia of approximately 30 minutes, and provides peak pain relief at $\sim 1-2$ hours, with overall effects lasting up to 6 hours..$^{17,18}$

The need for a medication that is efficacious, has a rapid onset of action, and has a relatively short duration of effect has led to the use of fentanyl - a rapid-onset opioid with anesthetic and analgesic properties - for the management of BTP. The first formulation of fentanyl that was approved for the management of BTP was oral transmucosal fentanyl citrate (OTFC) - a lozenge containing fentanyl citrate incorporated into a dissolvable sugar-based matrix. Since its Food and Drug Administration approval in 1998, several other fentanyl formulations and delivery routes have been developed for BTP management. Of note, however, fentanyl formulations are only indicated in patients with malignancies who are already receiving and who are tolerant to aroundthe-clock opioid therapy for their underlying persistent cancer pain. Use of fentanyl formulations for other types of BTP is currently off label. Fentanyl is also contraindicated in the management of acute or postoperative pain, including headache/migraine and dental pain. In December 2011, following concerns about misuse, abuse, addiction, overdose, and serious complications due to medication errors, a riskevaluation and -mitigation strategy was introduced for all transmucosal immediate-release fentanyl formulations. ${ }^{19}$

This review evaluates current pharmacologic methods of alleviating BTP and considers factors that should be taken into account when selecting the most appropriate formulation and delivery routes for individual patients.

\section{Fentanyl and fentanyl formulations}

Fentanyl is a $\mu$-opioid receptor agonist that is highly lipophilic, thereby enabling rapid diffusion across the blood-brain barrier and diffusion into central nervous system structures. ${ }^{20}$ It is 100 -fold more potent than morphine, ${ }^{21}$ and has an equilibration $t_{1 / 2}$ of 6 minutes, which facilitates rapid analgesia. It is metabolized in the liver by cytochrome P450 (CYP)-3A4; coadministration with CYP3A4 inhibitors can thus lead to increased fentanyl levels and an increased risk of respiratory depression. If patients are taking CYP3A4 inhibitors, they should be closely monitored and fentanyl dose increases should be carried out conservatively. ${ }^{22}$ In addition, use of fentanyl is not advised in patients who have taken monoamine oxidase inhibitors within the previous 14 days, ${ }^{23,24}$ and it should never be used in patients who are opioid intolerant. ${ }^{25}$ Fentanyl use can cause typical opioid-associated adverse events of nausea and vomiting, pruritus, and urinary retention; however, the most serious and potentially life-threatening adverse effect is respiratory failure due to severe hypoventilation. ${ }^{26,27}$

Fentanyl can be administered transdermally, intravenously, subcutaneously, oral transmucosally, or sublingually, and several fentanyl formulations are approved for the 
management of BTP (Table 1). ${ }^{22,28-33}$ All of the formulations approved for BTP have proven efficacy in reducing this pain in patients with cancer who are opioid tolerant; however, differences in administration routes affect the drug pharmacokinetics, which can influence some clinical parameters. An important consideration when considering the relative merits of the different formulations is the extent to which fentanyl is systemically absorbed and not ingested. It is desirable to avoid ingesting fentanyl, as it is associated with interindividual variability resulting from gastrointestinal and hepatic metabolism.

\section{Oral transmucosal fentanyl citrate}

OTFC (ACTIQ ${ }^{\circledR}$, Cephalon, Inc., Salt Lake City, UT, USA) is a buccal formulation composed of a sweetened fentanyl lozenge on a stick, which dissolves as the patient sweeps the lozenge over the inner portion of their cheek. It is approved in the US and Europe (the EU brand name is also ACTIQ) as treatment for BTP in adults with cancer pain who are receiving and are tolerant of opioid analgesics for underlying chronic cancer pain. Administration takes approximately 15 minutes, but the stick allows the OTFC unit to be removed if signs of excessive opioid effects are observed at any time. ${ }^{26,28}$ It is estimated that in normal circumstances, approximately $25 \%$ of the administered dose of OTFC is rapidly absorbed from the buccal mucosa and becomes systemically available, while the remaining $75 \%$ of the total dose is swallowed with saliva and then is slowly absorbed from the gastrointestinal tract. ${ }^{34}$ Approximately one-third of this amount (25\% of the total dose) escapes hepatic and intestinal first-pass elimination and becomes systemically available. Absorption via the buccal mucosa avoids first-pass metabolism, resulting in higher bioavailability than would be achieved through traditional oral administration. ${ }^{35}$

OTFC is available in 200, 400, 600, 800, 1200, and $1600 \mu \mathrm{g}$ strengths. ${ }^{28}$ Investigation of these doses showed that the pharmacokinetics are dose proportional, with $\mathrm{C}_{\max }$ and the area under the plasma concentration versus time curve (AUC) increasing linearly with increasing doses. Increasing the dose does not significantly affect the time taken to attain $\mathrm{C}_{\max }\left(\mathrm{T}_{\max }\right.$; median 20-40 minutes). ${ }^{35}$ The pharmacokinetics are similar between individuals and do not change with multiple dosing. ${ }^{36}$

Clinical trials of OTFC have mainly been conducted in patients with cancer who are receiving fixed schedules of around-the-clock opioids. In a placebo-controlled, double-blind, randomized, crossover study in opioidtolerant patients with cancer and BTP, OTFC produced significantly larger changes in pain intensity and better pain relief compared with placebo at time points from 15 minutes to 1 hour after administration $(P<0.0001) .{ }^{37}$ In addition, patients receiving OTFC required significantly less rescue medication than those receiving placebo (15\% vs $34 \%$ of episodes, respectively; $P<0.0001$ ).

In a randomized, double-blind crossover study of opioidtolerant patients with cancer in which the efficacy of OTFC was compared with immediate-release oral morphine sulfate, OTFC was significantly more effective across all time points when assessed by reductions in pain intensity $(P \leq 0.033)$, mean PID $(P<0.008)$, pain relief $(P \leq 0.009)$, and global performance rating $(P \leq 0.001) .{ }^{38}$ In addition, a clinically significant $\geq 33 \%$ change in PID at 15 minutes was reported for significantly more BTP episodes treated with OTFC than with the immediate-release morphine sulfate. Adverse effects observed with OTFC are typical of opioids and include somnolence, constipation, nausea, dizziness, and vomiting. ${ }^{37,39,40}$ Of particular note, OTFC has been shown to be relatively well tolerated in patients with radiation-induced oral mucositis (ulceration of the oral mucous membranes). ${ }^{41}$ However, due to the sugar content, concerns have been raised regarding the potential for dental decay with prolonged and repeated use. ${ }^{42}$

Reports of serious adverse events associated with OTFC, including deaths, have been reported. ${ }^{28}$ The deaths are believed to have occurred as a result of improper patient selection (eg, use in opioid-intolerant patients) and/or improper dosing. ${ }^{28}$ A lack of bioequivalence between different formulations means that substitution of OTFC for any other fentanyl product may result in fatal overdose. ${ }^{28}$

\section{Fentanyl buccal tablet}

Fentanyl buccal tablets (FBTs; FENTORA ${ }^{\circledR}$, Cephalon, Inc.) use OraVescent ${ }^{\circledR}$ delivery technology to enhance absorption of fentanyl across the buccal mucosa. They are approved in the US and Europe (EU brand name Effentora ${ }^{\circledR}$ ) as treatment for BTP in adults with cancer pain who are receiving and are tolerant of opioid analgesics for underlying chronic cancer pain. The delivery system initially produces carbon dioxide, leading to a decrease in $\mathrm{pH}$ in the microenvironment of the tablet, enhancing tablet dissolution. The carbon dioxide dissipates and sodium carbonate is released from the tablet, raising the $\mathrm{pH}$, which promotes absorption of fentanyl by the buccal mucosa. ${ }^{43,44}$ The OraVescent delivery system results in approximately $50 \%$ of fentanyl being absorbed transmucosally, with the remaining half of the total dose being swallowed and undergoing more prolonged absorption 


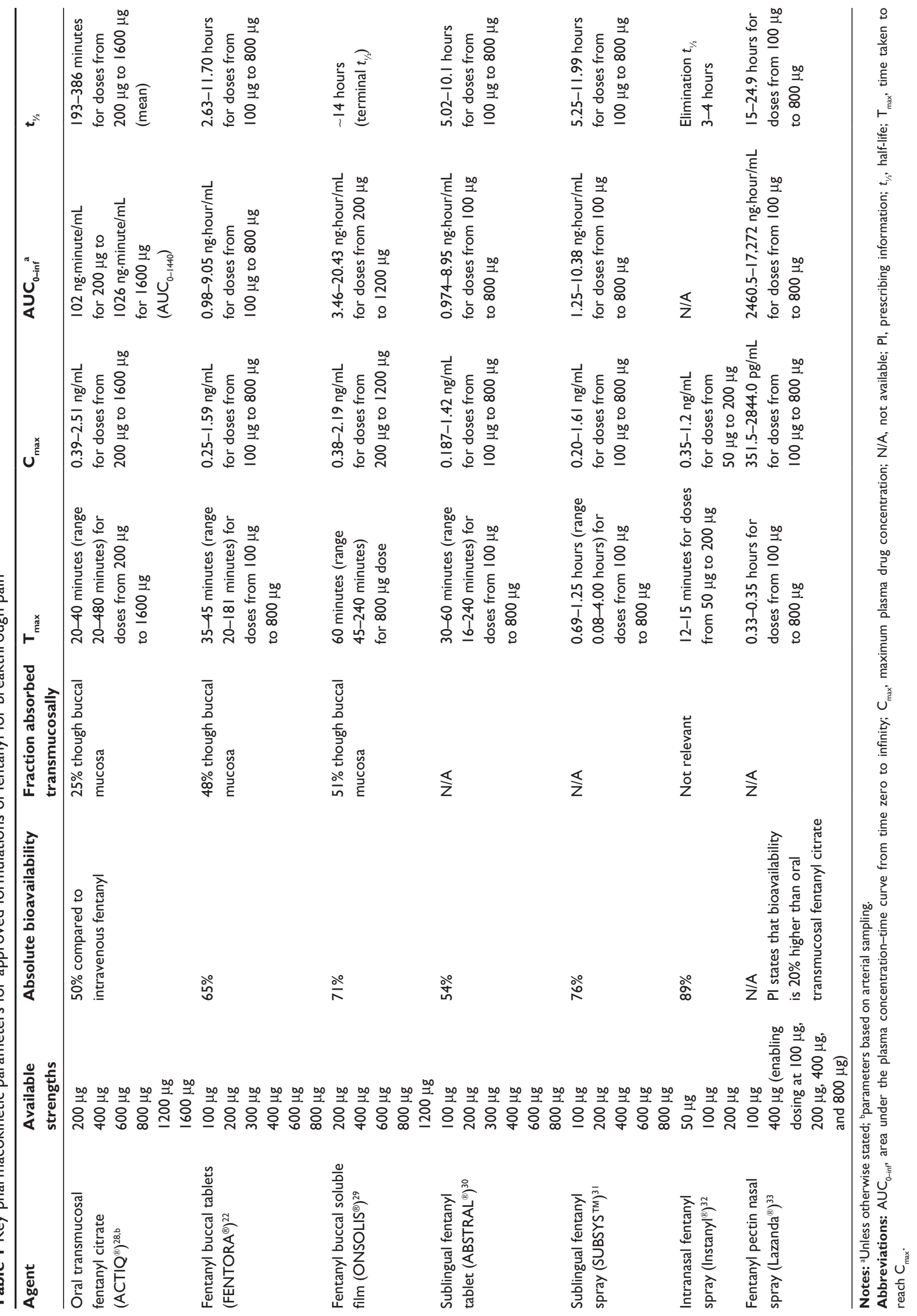


from the gastrointestinal tract. The dissolution process takes 14-25 minutes, although the rate and extent of fentanyl absorption through the buccal mucosa are not affected by differences in the dissolution time between patients. ${ }^{22,45}$

FBTs are available in doses of 100, 200, 400, 600, and $800 \mu \mathrm{g}$. Dose proportionality has been demonstrated up to $1300 \mu \mathrm{g}$ in healthy subjects, with predictable and linear increases in systemic exposure. ${ }^{46}$ Compared with OTFC, FBT enters the systemic circulation to a significantly greater extent (higher $\mathrm{C}_{\max }$ and $\mathrm{AUC}_{0-\mathrm{T} \max }$ ) and significantly faster (shorter $\left.\mathrm{T}_{\text {max }}\right),{ }^{47}$ which indicate that FBT could result in earlier onset of pain relief, although studies that directly compare the efficacy of OTFC and FBT have not been performed. ${ }^{48,49}$

The efficacy of FBT in the treatment of cancer and noncancer BTP in opioid-tolerant patients has been demonstrated in five placebo-controlled studies. ${ }^{50-54}$ Findings from these studies indicate that FBT demonstrates significant reductions in pain, as measured by summed PIDs (SPIDs) over 60 minutes and PID from 10 minutes, provides significant increases in pain relief from 10 minutes, and provides moderate and substantial clinically relevant improvements in pain intensity as early as 5 minutes. ${ }^{50-54}$ The efficacy of FBT in relieving pain is accompanied by lower rates of rescue medication compared with placebo. ${ }^{50-54}$

Although the efficacy of FBT has not been directly compared with that of OTFC, the efficacy of FBT and immediate-release oxycodone in alleviating BTP in opioidtolerant patients with chronic pain were recently compared. ${ }^{55}$ During the trial, the PIDs at 5, 10, 15, 30, and 60 minutes were significantly greater with FBT than oxycodone $(P<0.05$ at 5 minutes and $P<0.0001$ at all other time points). Furthermore, a clinically meaningful $\geq 33 \%$ improvement in pain intensity was observed in a larger proportion of FBT-treated episodes versus oxycodone from 15 through 45 minutes postdose $(P<0.05)$.

As with other fentanyl formulations, adverse effects observed with FBT are typical of opioids. The most common adverse events are nausea, dizziness, and vomiting. ${ }^{56}$ Application-site abnormalities have been reported by $5 \%-15 \%$ of patients in clinical studies of FBT, but are mainly transient and mild to moderate in severity. ${ }^{50,52-57}$

FBT is contraindicated in opioid-intolerant patients and in the management of acute or postoperative pain. Serious adverse events, including deaths, have been reported with FBT use, which may occur as a result of improper patient selection and/or improper dosing. As with all fentanyl products, the substitution of FBT for any other fentanyl product may result in fatal overdose.

\section{Fentanyl buccal soluble film}

Fentanyl buccal soluble film (FBSF; ONSOLIS ${ }^{\circledR}$, Meda Pharmaceuticals, Somerset, NJ, USA) uses BioErodible MucoAdhesive technology (BioDelivery Sciences International, Raleigh, NC, USA) to present fentanyl in a bilayer: an inner fentanyl-containing layer that adheres to the inside of the patient's cheek while an outer layer isolates the fentanyl-containing layer from saliva. The film dissolves within 15-30 minutes after application. The system reduces the quantity of fentanyl that is swallowed in the saliva and which would be consequently lost during firstpass metabolism, resulting in an absolute bioavailability of $71 \% .^{58}$ It was approved in the US in 2009 and in the EU in 2010 (EU trade name Breakyl ${ }^{\circledR}$ ) for BTP in adults with cancer who are receiving and who are tolerant of opioid analgesics for chronic cancer pain.

FBSF is available in doses of 200, 400, 600, 800, and $1200 \mu \mathrm{g}$ per film, with the different doses being proportional to the surface area of the film. The pharmacokinetics $\left(\mathrm{C}_{\max }\right.$ and overall exposure) have been demonstrated to be doseproportional across three dose levels $(200 \mu \mathrm{g}, 600 \mu \mathrm{g}$, and $1200 \mu \mathrm{g}$ ) in healthy volunteers, ${ }^{59}$ and there is minimal intraindividual variability in fentanyl absorption with this formulation. ${ }^{60} \mathrm{~A}$ recent study has also demonstrated that the pharmacokinetics of FBSF are broadly similar between patients with and without grade 1 mucositis. ${ }^{61}$ In a study of FBSF and OTFC in twelve healthy adult volunteers, the rate and extent of fentanyl absorption were considerably better with FBSF than with OTFC. ${ }^{6}$

The efficacy of FBSF 200-1200 $\mu \mathrm{g}$ was evaluated for the management of BTP in a placebo-controlled trial of patients with cancer receiving ongoing opioid therapy. The results showed that the SPID was significantly greater for FBSF-treated episodes of BTP than for placebo-treated episodes from 15 minutes postdose until 60 minutes postdose $(P<0.001) .{ }^{63}$ An unexpected finding during the study was a high placebo response rate. This was attributed to the innovative appearance of the buccal film used to administer both FBSF and placebo, which may have raised patient expectations and sensitized them to even slight changes in pain intensity. ${ }^{63}$ FBSF was well tolerated during the study, the most common drug-related adverse events being somnolence $(6.0 \%)$, nausea $(5.3 \%)$, dizziness $(4.6 \%)$, and vomiting $(4.0 \%)$.

\section{Sublingual fentanyl tablet}

The sublingual fentanyl tablet (SLFT; ABSTRAL ${ }^{\circledR}$, ProStrakan Inc., Bedminster, NJ, USA) is a rapidly disintegrating tablet 
comprising water-soluble carrier particles that are coated with fentanyl and a mucoadhesive agent to help keep the tablet under the tongue. The system increases exposure of the active agent to dissolving fluids at the absorption site and reduces the risk of swallowing. The overall bioavailability of SLFT is $54 \% .{ }^{30}$ It was approved in the EU in 2008 and in the US in 2011 (both under the brand name ABSTRAL) for BTP in opioid-tolerant adults with cancer.

SLFT is available in doses of 100, 200, 300, 600, and $800 \mu \mathrm{g}$, for which dose proportionality of pharmacokinetics has been demonstrated. ${ }^{30}$ In a pharmacokinetics study, fentanyl was first detected in plasma 8-11 minutes after administration, which suggests that this method of administration will have rapid clinical effects. ${ }^{64}$

In a randomized, placebo-controlled study of SLFT in 131 adult patients with cancer and BTP, use of SLFT resulted in significant improvements in SPID relative to placebo at 30 minutes (49.5 vs 36.6, $P=0.0004)$ and 60 minutes (143.0 vs $104.5, P=0.0002$ ) postadministration. Furthermore SLFT-treated patients had significant improvements in PID and pain relief compared with placebo from 10 minutes postdose $(P<0.05) .{ }^{65}$ In a separate phase III study evaluating long-term effectiveness of SLFT, patients reported high levels of satisfaction with the formulation; the levels of satisfaction did not diminish with prolonged treatment. ${ }^{66}$

Combined analysis of the two phase III studies revealed that SLFT was generally well tolerated; patients experienced adverse events typical of opioids, including nausea, constipation, somnolence, and headache. ${ }^{30}$

\section{Sublingual fentanyl spray}

Sublingual fentanyl spray (SLFS; SUBSYS тм, Insys Therapeutics, Inc., Phoenix, AZ, USA) is a liquid formulation of fentanyl, delivered sublingually via a singledose spray unit. It was approved in 2012 for use in the US in the management of BTP in adults with cancer who are receiving and are tolerant of opioid therapy for their underlying persistent cancer pain.

SLFS is available in doses of 100, 200, 400, 600 and $800 \mu \mathrm{g} /$ spray, which show dose-proportional pharmacokinetics in healthy volunteers. ${ }^{31}$ However, $\mathrm{C}_{\max }$ and the AUC from time zero to time of last measurable concentration were found to be increased in patients with cancer who had grade 1 or 2 mucositis compared with those without mucositis; the use of SLFS is therefore to be avoided in patients with grade 2 and higher mucositis, unless the expected benefits outweigh the risk of respiratory depression. ${ }^{31}$ In a comparison with OTFC in 21 healthy subjects, SLFS was found to have a shorter $\mathrm{T}_{\max }$ (median $1.5 \mathrm{~h}$ vs $2.0 \mathrm{~h}$ for OTFC), as well as $34 \%$ higher $\mathrm{C}_{\max }$ and $38 \%$ greater $\mathrm{AUC}_{0 \text {-inf }}{ }^{31}$

In a randomized, placebo-controlled study of SLFS in 98 adult patients with breakthrough cancer pain, use of SLFS resulted in significant improvements in SPID relative to placebo at 5 minutes (40.3 vs 32.0, $P=0.0219$ ), 30 minutes (640.3 vs 399.6, $P<0.0001$ ), and 60 minutes (1649.0 vs 965.7, $P<0.0001)$ postadministration. ${ }^{67}$ In addition, SLFS produced significantly greater pain relief (as evaluated by total pain relief) from 5 through 60 minutes $(P<0.0001)$. The most frequently reported adverse events were nausea $(7.1 \%)$, hyperhidrosis $(5.1 \%)$, and peripheral edema (5.1\%).

\section{Intranasal fentanyl spray}

Intranasal fentanyl spray (INFS; Instanyl ${ }^{\circledR}$, Nycomed Danmark, Roskilde, Denmark) was developed as an alternative method of delivering fentanyl for BTP, which may be particularly useful for patients with xerostomia or salivary gland dysfunction. It was approved in the EU in 2009 for BTP in adults with cancer who are receiving and who are tolerant of opioid analgesics for chronic cancer pain, but it has not been approved for use in the US.

INFS is available in doses of 50, 100, and $200 \mu \mathrm{g} / \mathrm{spray,}$ which show dose-proportional pharmacokinetics. ${ }^{32}$ It has a bioavailability of approximately $89 \%$, an onset of action within approximately 7 minutes and a duration of analgesic effect of approximately 1 hour. ${ }^{32}$

The efficacy of INFS 50-200 $\mu \mathrm{g} /$ spray compared with placebo was assessed in a phase III randomized trial in 120 opioid-tolerant patients with cancer and BTP. ${ }^{68}$ One hundred eleven patients identified an effective dose of INFS during a titration phase and entered the randomized stage of the study. All doses of INFS resulted in significantly higher pooled mean PID scores compared with placebo at 10, 20, 40, and 60 minutes $(P<0.001)$. The improved PID scores were accompanied by a reduced use of rescue medication in patients receiving INFS versus placebo (approximately $14 \%$ vs $45 \%$ of patients, respectively). A clinically meaningful reduction in pain ( $\geq 33 \%$ reduction) was noted at 10 minutes postdose for $57.7 \%$ of INFS treated patients compared with $28.3 \%$ of those who received placebo $(P<0.001) .{ }^{68}$

INFS (50-200 $\mu \mathrm{g})$ was compared with OTFC (200-1600 $\mu \mathrm{g})$ in an open-label study of 139 opioid-tolerant patients with cancer and BTP who had successfully identified a dose that gave effective analgesia in a preliminary titration phase. ${ }^{69}$ During the study, patients reported that meaningful pain relief was achieved in a median time of 11 minutes with INFS compared with 16 minutes for OTFC. In addition, 
approximately two-thirds of patients reported experiencing a faster onset of meaningful pain relief with INFS versus OTFC $(P<0.001) .{ }^{69}$ The adjusted mean PID was statistically significantly greater for INFS than OTFC across all time points from 5 minutes $(P<0.001)$ through to the final assessment at 60 minutes $(P<0.01){ }^{69}$ In this study, however, rescue medication usage for BTP was greater in patients receiving INFS than for those taking OTFC (7.8\% vs 4.9\%), which was attributed to the study-protocol requirement for patients to wait longer before rescue medication could be used after taking an OTFC dose (45-60 minutes) than after the first dose of INFS (20 minutes). ${ }^{69}$ The requirement was included in the trial because of the longer time needed for administration of the OTFC lozenge.

In addition to the anticipated opioid-related adverse events that were observed during the phase III clinical trial of INFS, vertigo was reported in two patients $(1.8 \%)$, and dizziness, myoclonus (severe muscle twitching), and dysgeusia (taste distortion) were reported in one patient each $(0.9 \%)$. Ulcers of the nasal mucosa were also reported in the above open-label study. ${ }^{69}$

\section{Fentanyl pectin nasal spray}

Fentanyl pectin nasal spray (FPNS; Lazanda ${ }^{\circledR}$, Archimedes Development Ltd, Bedminster, NJ, USA) uses a pectin-based delivery platform to administer fentanyl. Upon contact with the nasal mucosa, the FPNS spray forms a thin layer of flexible gel that modulates delivery of the fentanyl and reduces nasal runoff (either nasal drip or swallowing). ${ }^{70,71}$ It was approved in the EU in 2010 (trade name PecFent ${ }^{\mathbb{B}}$ ) and in the US in 2011 for BTP in adults with cancer who are receiving and who are tolerant of opioid analgesics for chronic cancer pain.

FPNS is available in doses of 100 and $400 \mu \mathrm{g}$ /application, which enables dosing up to $800 \mu \mathrm{g}$ if sprayed once in each nostril. The pharmacokinetics are dose-proportional up to $800 \mu \mathrm{g}$. In a study that compared FPNS with OTFC in 16 opioid-naive healthy subjects, FPNS had a shorter $\mathrm{T}_{\max }$ than OTFC (15-21 vs 90 minutes, respectively, $P<0.01$ ), higher $\mathrm{C}_{\max }$ (2.3-fold higher for FPNS vs OTFC), and greater bioavailability than OTFC. ${ }^{70}$

FPNS was evaluated against placebo in a randomized study of 114 opioid-tolerant patients with cancer and BTP. $^{72}$ For the 83 patients for whom an effective dose of FPNS was established, SPID was significantly greater with FPNS compared with placebo from 10 minutes $(P<0.05)$ until 60 minutes $(P<0.0001)$ after application. Pain-intensity scores improved from as early as 5 minutes postdose, PID from 10 minutes $(P<0.01)$, and pain-relief scores from 10 minutes $(P<0.001)$. The reductions in pain observed with FPNS were accompanied by significantly reduced use of rescue medication during the 60 minutes following dosing $(P<0.001)$.

In a recent study in which FPNS was compared with oral immediate-release morphine sulfate in 110 patients with chronic cancer pain and BTP, ${ }^{73}$ clinically meaningful improvements in pain intensity ( $\geq 2$-point reduction on an 11-point numeric scale) from 10 minutes after dosing were reported for a significantly higher proportion of BTP episodes treated with FPNS than those treated with immediate-release morphine $(52.4 \%$ vs $45.4 \%, P<0.05)$. Rescue-medication usage was similar for the two treatments $(3.0 \%$ and $3.8 \%$ of FPNS- and morphine sulfate-treated BTP episodes, respectively, $P=0.57){ }^{73}$

The main adverse events reported by patients treated with FPNS were those typically related to opioid use, although epistaxis and nasopharyngitis were reported in $4.4 \%$ and $3.5 \%$ of FPNS-treated patients, respectively $(n=113) .{ }^{72}$

\section{Considerations when selecting rapid-onset opioids for breakthrough pain}

When evaluating the characteristics of BTP, consideration should be given to whether it is a result of end-of-dose failure, in which case alterations to the around-the-clock medication may be more appropriate than the addition of a rapid-onset opioid.

Although the efficacy of all of the available agents for BTP has been demonstrated in placebo-controlled clinical trials, a lack of head-to-head evaluations makes it challenging for physicians to select the most appropriate treatment based on efficacy alone. Meta-analyses and systematic reviews of available formulations have been attempted, but differences between the populations and design of the clinical trials may affect the efficacy results and preclude the ability to draw firm conclusions regarding the most efficacious intervention. ${ }^{74}$ Such differences include patient selection criteria, severity of BTP episodes, the proportion of patients with a neuropathic pain component, titration protocols, choice of primary end points, protocols for repeat dosing and use of rescue medication, the separation of treated episodes, and the extent of placebo response.

In the absence of clear data on the relative efficacy of these products, prescribing decisions will most likely be made on the basis of the advantages and disadvantages of the different routes of administration. 
Although clearly efficacious for the management of BTP, numerous advantages and disadvantages of the different methods of administration have been suggested (Table 2), (which may make some formulations more suitable for particular patient groups than others). ${ }^{22,28-30,32,33,37,51,63,65,67,68,72,75}$ Factors that should be considered when selecting the most appropriate formulation include individual patient characteristics, likelihood of adherence, characteristics of their BTP, and formulation preferences. Patient attributes that may be relevant include a lack of physical dexterity or weakness; this may make administration of OTFC more difficult because it requires active patient participation. The presence of xerostomia may make some oral medications more difficult to administer for affected patients. Mucositis, which is a common problem in patients with cancer, may also influence the choice of an appropriate formulation, although studies with FBT, SLFT, and OTFC have shown that these interventions are well tolerated in patients with mucositis. ${ }^{41,61,76}$

There are surprisingly few data on patient preferences for BTP interventions. Some indication of preference can be found in the few clinical trials in which an active comparator was included. For example, in an open-label, randomized trial in which INFS was compared with OTFC for the treatment of BTP, more patients preferred INFS than OTFC (77.4\% vs $22.6 \%, P<0.001)$ and more patients found

Table 2 Potential advantages and disadvantages of different routes for available breakthrough pain treatments (adapted from Nicholson and Agarwala ${ }^{75}$ and product prescribing information) $)^{22,28-30,32,33}$

\begin{tabular}{|c|c|c|c|}
\hline $\begin{array}{l}\text { Administration route } \\
\text { Available formulations }\end{array}$ & Advantages & Disadvantages & $\begin{array}{l}\text { Pivotal } \\
\text { clinical trials }\end{array}$ \\
\hline $\begin{array}{l}\text { Oral transmucosal } \\
\text { Oral transmucosal fentanyl citrate } \\
\left(\mathrm{ACTIQ}^{\circledR}\right)\end{array}$ & $\begin{array}{l}\text { The mucosally absorbed dose ( } 25 \%) \\
\text { bypasses hepatic first-pass metabolism } \\
\text { Rapid onset of action } \\
\text { Cessation of drug administration is } \\
\text { feasible if toxicity develops } \\
\text { Can be used for pediatric and geriatric } \\
\text { patients } \\
\text { Can be used by patients who are unable } \\
\text { to swallow or find medications difficult } \\
\text { to swallow due to nausea/vomiting }\end{array}$ & $\begin{array}{l}\text { Relatively low surface area for absorption } \\
\text { May be difficult for patients with dry mouth/ } \\
\text { mucositis } \\
\text { The "lollipop" may be perceived } \\
\text { as childish } \\
\text { Potential for dental decay with prolonged use } \\
\text { Absorption can be variable } \\
\text { Patients may require training on correct use } \\
\text { Takes time to dissolve }\end{array}$ & Farrar et $\mathrm{al}^{37}$ \\
\hline $\begin{array}{l}\text { Transbuccal } \\
\text { Fentanyl buccal tablets (FENTORA }{ }^{\circledR} \text { ) }\end{array}$ & $\begin{array}{l}\text { The mucosally absorbed dose ( } 48 \% \text { with } \\
\text { buccal tablets; } 51 \% \text { with soluble film) }\end{array}$ & $\begin{array}{l}\text { Lower permeability via buccal membrane } \\
\text { compared with sublingual membrane }\end{array}$ & $\begin{array}{l}\text { Portenoy et al } \\
\left.\text { (FENTORA }^{\circledR}\right)^{51}\end{array}$ \\
\hline Fentanyl buccal soluble film (ONSOLIS ${ }^{\circledR}$ & $\begin{array}{l}\text { bypasses hepatic first-pass metabolism } \\
\text { Rapid onset of action } \\
\text { Greater bioavailability than oral } \\
\text { transmucosal products } \\
\text { Can be used by patients who are unable } \\
\text { to swallow or find medications difficult } \\
\text { to swallow due to nausea/vomiting }\end{array}$ & $\begin{array}{l}\text { Smaller surface area for absorption } \\
\text { May be difficult for patients with dry } \\
\text { mouth/mucositis }\end{array}$ & $\begin{array}{l}\text { Rauck et al } \\
\left(\text { ONSOLIS }{ }^{\circledR 3}\right.\end{array}$ \\
\hline $\begin{array}{l}\text { Sublingual } \\
\text { Sublingual fentanyl tablet }\left(A B S T R A L^{\circledR}\right)\end{array}$ & $\begin{array}{l}\text { The mucosally absorbed dose bypasses } \\
\text { hepatic first-pass metabolism }\end{array}$ & $\begin{array}{l}\text { May be difficult for patients with dry } \\
\text { mouth/mucositis }\end{array}$ & $\begin{array}{l}\text { Rauck et al } \\
\left(\text { ABSTRAL }^{\circledast}\right)^{65}\end{array}$ \\
\hline Sublingual fentanyl spray (SUBSYS ${ }^{\mathrm{TM}}$ ) & $\begin{array}{l}\text { Rapid onset of action } \\
\text { Can be used by patients who are unable } \\
\text { to swallow or find medications difficult } \\
\text { to swallow due to nausea/vomiting }\end{array}$ & $\begin{array}{l}\text { Drug and delivery system may be ingested } \\
\text { in saliva } \\
\text { May be limited to lower doses }\end{array}$ & $\begin{array}{l}\text { Rauck et al } \\
\left(\text { SUBSYS }^{\mathrm{TM}}\right)^{67}\end{array}$ \\
\hline $\begin{array}{l}\text { Intranasal } \\
\text { Intranasal fentanyl spray }\left(\text { Instany }\left.\right|^{\circledR}\right)\end{array}$ & $\begin{array}{l}\text { The systemically absorbed dose bypasses } \\
\text { hepatic first-pass metabolism }\end{array}$ & $\begin{array}{l}\text { Patients may require training in the correct } \\
\text { administration technique for intranasal sprays }\end{array}$ & $\begin{array}{l}\text { Kress et al } \\
\left(\text { Instany }\left.\right|^{\circledR}\right)^{68}\end{array}$ \\
\hline Fentanyl pectin nasal spray $\left(\right.$ Lazanda $\left.^{\circledR}\right)$ & $\begin{array}{l}\text { Can be administered by caregivers } \\
\text { Rapid onset of action } \\
\text { Convenient } \\
\text { Can be used by patients who are unable } \\
\text { to swallow or find medications difficult } \\
\text { to swallow due to nausea/vomiting }\end{array}$ & $\begin{array}{l}\text { Potential for application-site adverse effects. } \\
\text { including nasal irritation } \\
\text { Potentially unsuitable for patients with colds } \\
\text { or illnesses that result in changes to the nasal } \\
\text { mucosa } \\
\text { Quantity of drug absorbed may be variable } \\
\text { Nasal drip or swallowing can affect absorption } \\
\text { May be difficult for patients lacking manual } \\
\text { dexterity } \\
\text { Dose limited to }<0.2 \mathrm{~mL}\end{array}$ & $\begin{array}{l}\text { Portenoy et al } \\
\left(\text { Lazanda }^{\circledR}\right)^{72}\end{array}$ \\
\hline
\end{tabular}

Note: ${ }^{\mathrm{A}} \mathrm{CCTIQ}$ is not indicated for use in pediatric patients. 
it very easy/easy to use.$^{69}$ In a study comparing FBT with immediate-release oxycodone, FBT was preferred by $52 \%$ of patients compared with $33 \%$ for oxycodone.${ }^{55}$ Similarly in a comparison of FBT with previous traditional short-acting opioids (eg, oral morphine, oxycodone, or hydrocodone), more patients reported that they preferred FBT to their previous BTP medication, ${ }^{57}$ stating reasons such as speed of action, convenience, and ease of administration of $\mathrm{FBT}^{57}$

An evaluation of the acceptability of different routes of analgesia for BTP in patients with cancer-related BTP was conducted in 2004 to assess the potential acceptability of some of the newer routes of administration that were being developed. Overall findings from the study were that $97 \%$, $50 \%, 63 \%$, and $44 \%$ of patients reported that they would find it acceptable to take oral, nasal, sublingual, and buccal medications, respectively, for mild/moderate BTP ; for severe BTP the rates were $88 \%, 68 \%, 75 \%$, and $63 \%$, respectively. ${ }^{77}$ Experience of different routes of administration may have played an important part in the overall findings. All of the patients were familiar with using oral medications, but only $2 \%$ of respondents had previous experience of using buccal medications (the OTFC lozenge on a stick), 16\% had prior experience of nasally delivered medications, and $32 \%$ had experience of sublingual medications. For many patients, unfamiliarity was stated as a major reason for finding this treatment modality unacceptable. Respondents expressed concerns about the potential for an unpleasant taste/nausea with buccal, nasal, and inhaled medications for BTP and the childish appearance of the OTFC "lollipop." In addition, some patients reported previous bad experiences with sublingual and inhaled medications as further motives for rejection. ${ }^{77}$

Previous experience of a particular route of administration was also associated with higher rates of acceptance in a study of 320 patients in Northern Europe with cancer and BTP. ${ }^{78}$ In this study, patients were questioned about the characteristics and current management of their pain, and the acceptability/utility of alternative routes of administration. Sixty-five percent of patients reported that they would definitely consider using an oral transmucosal product, even though $73 \%$ of patients regularly reported experiencing oral problems. ${ }^{78}$ Forty-two percent of patients reported that they would definitely consider using an intranasal product, with $26 \%$ stating they would definitely not use such a preparation. Forty-four percent of patients reported regular nasal problems. Sixty percent of patients reported that they would definitely consider using a subcutaneous product, and $44 \%$ of patients would definitely consider using an intrapulmonary product.
In light of growing concerns about the potential abuse of opioids, including rapid-onset opioids, clinicians should conduct a thorough medical history, including assessment of the risk of substance abuse, misuse, or addiction. ${ }^{41,76,79}$ Screening tools that can be useful for risk stratification include the Screener and Opioid Assessment for Patients with Pain, the Diagnosis, Intractability, Risk, and Efficacy inventory, and/or the Opioid Risk Tool. ${ }^{80}$

Acute use of opioid formulations can potentially result in the development of hyperalgesia and/or acute tolerance; ${ }^{81}$ however there has been little investigation into this occurring in conjunction with the use of fentanyl formulations for BTP.

An important consideration when changing a patient's medication for BTP is the lack of bioequivalence between different fentanyl formulations, which means that the dose must be titrated specifically for the formulation to avoid potentially life-threatening effects of overdose. The majority of studies of fentanyl formulations have included a dosetitration phase so that individual patients can identify the dose of the formulation that provides them with the best balance of efficacy and tolerability.

\section{Conclusion}

Recent years have seen the introduction of a range of fentanyl formulations for the management of BTP in patients with malignancies who are already receiving and who are tolerant to around-the-clock opioid therapy; however, in the absence of comprehensive head-to-head trials, there are few data to guide clinicians on the most efficacious or best-tolerated formulations. Different administration routes may make some formulations more suitable and/or preferable for individual patients. With this in mind, prescribing decisions will need to be based on physician understanding and experience, availability of products, and relative costs, taking into account the individual patient's needs, the ability of the patient or caregivers to administer medication, and the patient's wishes. With the onus on physicians to make prescribing decisions, it is imperative that they are aware of the advantages and disadvantages of individual formulations in order to provide the optimal intervention for an individual patient's BTP; however, with the range of formulations available, it is now possible to address BTP in the majority of patients.

\section{Acknowledgments}

Medical writing support was provided by Lucy Kanan of Anthemis Consulting Ltd and was funded by Teva Pharmaceuticals Industries Ltd, Frazer, PA, USA. Teva provided a single medical accuracy review of the final draft. 
Dr Smith was not compensated and retained full editorial control over the content of the paper.

\section{Disclosure}

No conflicts of interest to disclose.

\section{References}

1. Caraceni A, Martini C, Zecca E, et al. Breakthrough pain characteristics and syndromes in patients with cancer pain. An international survey. Palliat Med. 2004;18:177-183.

2. Portenoy RK, Hagen NA. Breakthrough pain: definition, prevalence and characteristics. Pain. 1990;41:273-281.

3. Portenoy RK, Bennett DS, Rauck R, et al. Prevalence and characteristics of breakthrough pain in opioid-treated patients with chronic noncancer pain. J Pain. 2006;7:583-591.

4. Portenoy RK, Bruns D, Shoemaker B, Shoemaker SA. Breakthrough pain in community-dwelling patients with cancer pain and noncancer pain, part 1: prevalence and characteristics. J Opioid Manag. 2010;6:97-108.

5. Christrup LL, Lundorff L, Werner M. Novel formulations and routes of administration for opioids in the treatment of breakthrough pain. Therapy. 2009;6:695-706.

6. Abernethy AP, Wheeler JL, Fortner BV. A health economic model of breakthrough pain. Am J Manag Care. 2008;14:S129-S140.

7. Burton B, Zeppetella G. Assessing the impact of breakthrough cancer pain. BrJ Nurs. 2011;20:S14, S16-S19.

8. Dickman A. Integrated strategies for the successful management of breakthrough cancer pain. Curr Opin Support Palliat Care. 2011;5: 8-14.

9. Fortner BV, Okon TA, Portenoy RK. A survey of pain-related hospitalizations, emergency department visits, and physician office visits reported by cancer patients with and without history of breakthrough pain. J Pain. 2002;3:38-44.

10. Taylor DR, Webster LR, Chun SY, et al. Impact of breakthrough pain on quality of life in patients with chronic, noncancer pain: patient perceptions and effect of treatment with oral transmucosal fentanyl citrate (OTFC, ACTIQ). Pain Med. 2007;8:281-288.

11. Payne R. Recognition and diagnosis of breakthrough pain. Pain Med. 2007;8 Suppl 1:S3-S7.

12. Farrar JT, Berlin JA, Strom BL. Clinically important changes in acute pain outcome measures: a validation study. J Pain Symptom Manage. 2003;25:406-411

13. Collins SL, Faura CC, Moore RA, McQuay HJ. Peak plasma concentrations after oral morphine: a systematic review. J Pain Symptom Manage. 1998;16:388-402.

14. Lotsch J. Pharmacokinetic-pharmacodynamic modeling of opioids. J Pain Symptom Manage. 2005;29:S90-S103.

15. Mercadante S, Radbruch L, Caraceni A, et al. Episodic (breakthrough) pain: consensus conference of an expert working group of the European Association for Palliative Care. Cancer. 2002;94:832-839.

16. Zeppetella G. Dynamics of breakthrough pain vs pharmacokinetics of oral morphine: implications for management. Eur J Cancer Care (Engl). 2009;18:331-337.

17. Zeppetella G. Opioids for cancer breakthrough pain: a pilot study reporting patient assessment of time to meaningful pain relief. $J$ Pain Symptom Manage. 2008;35:563-567.

18. Hoeben E, Smit JW, Upmalis D, et al. Dose-response relationship after single oral dose administrations of morphine and oxycodone using laser-evoked potentials on UVB- and capsaicin-irritated skin in healthy male subjects. Pain. 2012;153:1648-1656.

19. Food and Drug Administration. Transmucosal immediate release fentanyl (TIRF) risk evaluation and mitigation strategy (REMS). 2012. Available from: http://www.fda.gov/downloads/Drugs/DrugSafety/ PostmarketDrugSafetyInformationforPatientsandProviders/ UCM289730.pdf. Accessed January 23, 2013.
20. Scott JC, Ponganis KV, Stanski DR. EEG quantitation of narcotic effect: the comparative pharmacodynamics of fentanyl and alfentanil. Anesthesiology. 1985;62:234-241.

21. Grape S, Schug SA, Lauer S, Schug BS. Formulations of fentanyl for the management of pain. Drugs. 2010;70:57-72.

22. Cephalon. FENTORA ${ }^{\circledR}$ (fentanyl buccal tablet) [package insert]. Salt Lake City: Cephalon, Inc.; 2011.

23. Browne B, Linter S. Monoamine oxidase inhibitors and narcotic analgesics. A critical review of the implications for treatment. $\mathrm{Br} J$ Psychiatry. 1987;151:210-212.

24. Insler SR, Kraenzler EJ, Licina MG, Savage RM, Starr NJ. Cardiac surgery in a patient taking monoamine oxidase inhibitors: an adverse fentanyl reaction. Anesth Analg. 1994;78:593-597.

25. Food and Drug Administration. FDA warns of potential serious side effects with breakthrough cancer pain drug [press release]. Silver Spring (MD): FDA; September 26, 2007. Available from: http://www.fda.gov/ NewsEvents/Newsroom/PressAnnouncements/2007/ucm108994.htm. Accessed June 1, 2011.

26. Knill R, Cosgrove JF, Olley PM, Levison H. Components of respiratory depression after narcotic premedication in adolescents. Can Anaesth Soc J. 1976;23:449-458.

27. Rigg JR, Goldsmith CH. Recovery of ventilatory response to carbon dioxide after thiopentone, morphine and fentanyl in man. Can Anaesth Soc J. 1976;23:370-382.

28. Cephalon. ACTIQ ${ }^{\circledR}$ (oral transmucosal fentanyl citrate) [package insert]. Salt Lake City: Cephalon, Inc.; 2011.

29. Meda Pharmaceuticals. ONSOLIS ${ }^{\circledR}$ (fentanyl buccal soluble film) [package insert]. Somerset (NJ): Meda Pharmaceuticals, Inc.; 2009.

30. ProStrakan. ABSTRAL ${ }^{\circledR}$ (fentanyl sublingual tablets) [package insert]. Bedminster (NJ): ProStrakan, Inc.; 2011.

31. Insys Therapeutics. SUBSYS ${ }^{\text {тм }}$ (fentanyl sublingual spray) [package insert]. Phoenix: Insys Therapeutics, Inc.; 2012.

32. Nycomed Danmark. Instanyl ${ }^{\circledR}$ (intranasal fentanyl nasal spray) [summary of product characteristics]. Roskilde, Denmark: Nycomed Danmark ApS; 2011.

33. Archimedes Pharma. Lazanda ${ }^{\circledR}$ (fentanyl pectin nasal spray) [package insert]. Bedminster (NJ): Archimedes Pharma, Inc.; 2011.

34. Mystakidou K, Katsouda E, Parpa E, Tsiatas ML, Vlahos L. Oral transmucosal fentanyl citrate for the treatment of breakthrough pain in cancer patients: an overview of its pharmacological and clinical characteristics. J Opioid Manag. 2005;1:36-40.

35. Streisand JB, Busch MA, Egan TD, Smith BG, Gay M, Pace NL. Dose proportionality and pharmacokinetics of oral transmucosal fentanyl citrate. Anesthesiology. 1998;88:305-309.

36. Egan TD, Sharma A, Ashburn MA, Kievit J, Pace NL, Streisand JB. Multiple dose pharmacokinetics of oral transmucosal fentanyl citrate in healthy volunteers. Anesthesiology. 2000;92:665-673.

37. Farrar JT, Cleary J, Rauck R, Busch M, Nordbrock E. Oral transmucosal fentanyl citrate: randomized, double-blinded, placebo-controlled trial for treatment of breakthrough pain in cancer patients. J Natl Cancer Inst. 1998;90:611-616.

38. Coluzzi PH, Schwartzberg L, Conroy JD, et al. Breakthrough cancer pain: a randomized trial comparing oral transmucosal fentanyl citrate (OTFC) and morphine sulfate immediate release (MSIR). Pain. 2001;91:123-130.

39. Christie JM, Simmonds M, Patt R, et al. Dose-titration, multicenter study of oral transmucosal fentanyl citrate for the treatment of breakthrough pain in cancer patients using transdermal fentanyl for persistent pain. J Clin Oncol. 1998;16:3238-3245.

40. Portenoy RK, Payne R, Coluzzi P, et al. Oral transmucosal fentanyl citrate (OTFC) for the treatment of breakthrough pain in cancer patients: a controlled dose titration study. Pain. 1999;79: 303-312.

41. Shaiova L, Lapin J, Manco LS. Tolerability and effects of two formulations of oral transmucosal fentanyl citrate (OTFC; ACTIQ) in patients with radiation-induced oral mucositis. Support Care Cancer. $2004 ; 12: 268-273$ 
42. Mystakidou K, Katsouda E, Parpa E, Tsiatas ML, Vlahos L. Oral transmucosal fentanyl citrate for the treatment of breakthrough pain in cancer patients: an overview of its pharmacological and clinical characteristics. Am J Hosp Palliat Care. 2005;22:228-232.

43. Durfee S, Messina J, Khankari R. Fentanyl effervescent buccal tablets. Am J Drug Deliv. 2006;4:1-5.

44. Pather SI, Siebert JM, Hontz J, Khankari RK, Gupte SV, Kumbale R. Enhanced buccal delivery of fentanyl using the oravescent drug delivery system. Drug Deliv Technol. 2001;1:54-57.

45. Darwish M, Kirby M, Jiang JG. Effect of buccal dwell time on the pharmacokinetic profile of fentanyl buccal tablet. Expert Opin Pharmacother. 2007;8:2011-2016.

46. Darwish M, Kirby M, Robertson P Jr, Tracewell W, Xie F. Dose proportionality of fentanyl buccal tablet in doses ranging from 600 to 1300 microg in healthy adult subjects: a randomized, open-label, four-period, crossover, single-centre study. Clin Drug Investig. 2010;30:365-373.

47. Darwish M, Tempero K, Kirby M, Thompson J. Relative bioavailability of the fentanyl effervescent buccal tablet (FEBT) 1,080 pg versus oral transmucosal fentanyl citrate $1,600 \mathrm{pg}$ and dose proportionality of FEBT 270 to 1,300 microg: a single-dose, randomized, open-label, three-period study in healthy adult volunteers. Clin Ther. 2006;28:715-724.

48. Darwish M, Kirby M, Robertson P Jr, Tracewell W, Jiang JG. Pharmacokinetic properties of fentanyl effervescent buccal tablets: a phase I, open-label, crossover study of single-dose 100, 200, 400, and 800 microg in healthy adult volunteers. Clin Ther. 2006;28: 707-714.

49. Darwish M, Kirby M, Robertson P Jr, Tracewell W, Jiang JG. Absolute and relative bioavailability of fentanyl buccal tablet and oral transmucosal fentanyl citrate. J Clin Pharmacol. 2007;47:343-350.

50. Farrar JT, Messina J, Xie F, Portenoy RK. A novel 12-week study, with three randomized, double-blind placebo-controlled periods to evaluate fentanyl buccal tablets for the relief of breakthrough pain in opioid-tolerant patients with noncancer-related chronic pain. Pain Med. 2010;11:1313-1327.

51. Portenoy RK, Taylor D, Messina J, Tremmel L. A randomized, placebo-controlled study of fentanyl buccal tablet for breakthrough pain in opioid-treated patients with cancer. Clin J Pain. 2006;22: $805-811$

52. Portenoy RK, Messina J, Xie F, Peppin J. Fentanyl buccal tablet (FBT) for relief of breakthrough pain in opioid-treated patients with chronic low back pain: a randomized, placebo-controlled study. Curr Med Res Opin. 2007;23:223-233.

53. Simpson DM, Messina J, Xie F, Hale M. Fentanyl buccal tablet for the relief of breakthrough pain in opioid-tolerant adult patients with chronic neuropathic pain: a multicenter, randomized, double-blind, placebo-controlled study. Clin Ther. 2007;29:588-601.

54. Slatkin NE, Xie F, Messina J, Segal TJ. Fentanyl buccal tablet for relief of breakthrough pain in opioid-tolerant patients with cancer-related chronic pain. J Support Oncol. 2007;5:327-334.

55. Ashburn MA, Slevin KA, Messina J, Xie F. The efficacy and safety of fentanyl buccal tablet compared with immediate-release oxycodone for the management of breakthrough pain in opioid-tolerant patients with chronic pain. Anesth Analg. 2011;112:693-702.

56. Weinstein SM, Messina J, Xie F. Fentanyl buccal tablet for the treatment of breakthrough pain in opioid-tolerant patients with chronic cancer pain: a long-term, open-label safety study. Cancer. 2009;115:2571-2579.

57. Fine PG, Messina J, Xie F, Rathmell J. Long-term safety and tolerability of fentanyl buccal tablet for the treatment of breakthrough pain in opioid-tolerant patients with chronic pain: an 18-month study. J Pain Symptom Manage. 2010;40:747-760.

58. Vasisht N, Gever LN, Tagarro I, Finn AL. Single-dose pharmacokinetics of fentanyl buccal soluble film. Pain Med. 2010;11:1017-1023.

59. Finn AL, Vasisht N, Stark JG, Gever LN, Tagarro I. Dose proportionality and pharmacokinetics of fentanyl buccal soluble film in healthy subjects: a phase I, open-label, three-period, crossover study. Clin Drug Investig. 2012;32:63-71.
60. Davies A, Finn A, Tagarro I. Intra- and interindividual variabilities in the pharmacokinetics of fentanyl buccal soluble film in healthy subjects: a cross-study analysis. Clin Drug Investig. 2011;31:317-324.

61. Finn AL, Hill WC, Tagarro I, Gever LN. Absorption and tolerability of fentanyl buccal soluble film (FBSF) in patients with cancer in the presence of oral mucositis. J Pain Res. 2011;4:245-251.

62. Vasisht N, Gever LN, Tagarro I, Finn AL. Formulation selection and pharmacokinetic comparison of fentanyl buccal soluble film with oral transmucosal fentanyl citrate: a randomized, open-label, single-dose, crossover study. Clin Drug Investig. 2009;29:647-654.

63. Rauck R, North J, Gever LN, Tagarro I, Finn AL. Fentanyl buccal soluble film (FBSF) for breakthrough pain in patients with cancer: a randomized, double-blind, placebo-controlled study. Ann Oncol. 2010;21:1308-1314.

64. Lennernas B, Hedner T, Holmberg M, Bredenberg S, Nystrom C, Lennernas H. Pharmacokinetics and tolerability of different doses of fentanyl following sublingual administration of a rapidly dissolving tablet to cancer patients: a new approach to treatment of incident pain. Br J Clin Pharmacol. 2005;59:249-253.

65. Rauck RL, Tark M, Reyes E, et al. Efficacy and long-term tolerability of sublingual fentanyl orally disintegrating tablet in the treatment of breakthrough cancer pain. Curr Med Res Opin. 2009;25: 2877-2885.

66. Nalamachu S, Hassman D, Wallace MS, Dumble S, Derrick R, Howell J. Long-term effectiveness and tolerability of sublingual fentanyl orally disintegrating tablet for the treatment of breakthrough cancer pain. Curr Med Res Opin. 2011;27:519-530.

67. Rauck R, Reynolds L, Geach J, et al. Efficacy and safety of fentanyl sublingual spray for the treatment of breakthrough cancer pain: a randomized, double-blind, placebo-controlled study. Curr Med Res Opin. 2012;28:859-870.

68. Kress HG, Oronska A, Kaczmarek Z, Kaasa S, Colberg T, Nolte T. Efficacy and tolerability of intranasal fentanyl spray 50 to 200 microg for breakthrough pain in patients with cancer: a phase III, multinational, randomized, double-blind, placebo-controlled, crossover trial with a 10-month, open-label extension treatment period. Clin Ther. 2009;31:1177-1191

69. Mercadante S, Radbruch L, Davies A, et al. A comparison of intranasal fentanyl spray with oral transmucosal fentanyl citrate for the treatment of breakthrough cancer pain: an open-label, randomised, crossover trial. Curr Med Res Opin. 2009;25:2805-2815.

70. Fisher A, Watling M, Smith A, Knight A. Pharmacokinetics and relative bioavailability of fentanyl pectin nasal spray 100-800 microg in healthy volunteers. Int J Clin Pharmacol Ther. 2010;48:860-867.

71. Watts P, Smith A. PecSys: in situ gelling system for optimised nasal drug delivery. Expert Opin Drug Deliv. 2009;6:543-552.

72. Portenoy RK, Burton AW, Gabrail N, Taylor D. A multicenter, placebo-controlled, double-blind, multiple-crossover study of fentanyl pectin nasal spray (FPNS) in the treatment of breakthrough cancer pain. Pain. 2010;151:617-624.

73. Davies A, Sitte T, Elsner F, et al. Consistency of efficacy, patient acceptability, and nasal tolerability of fentanyl pectin nasal spray compared with immediate-release morphine sulfate in breakthrough cancer pain. J Pain Symptom Manage. 2011;41:358-366.

74. Elsner F, Zeppetella G, Porta-Sales J, Tagarro I. Newer generation fentanyl transmucosal products for breakthrough pain in opioid-tolerant cancer patients. Clin Drug Investig. 2011;31:605-618.

75. Nicholson B, Agarwala SS. Opioid delivery in the treatment of cancer breakthrough pain: a review of routes of administration. $J$ Opioid Manag. 2011;7:69-79.

76. Darwish M, Kirby M, Robertson P, Tracewell W, Jiang JG. Absorption of fentanyl from fentanyl buccal tablet in cancer patients with or without oral mucositis: a pilot study. Clin Drug Investig. 2007;27:605-611.

77. Walker G, Wilcock A, Manderson C, Weller R, Crosby V. The acceptability of different routes of administration of analgesia for breakthrough pain. Palliat Med. 2003;17:219-221. 
78. Davies A, Zeppetella G, Andersen S, et al. Multi-centre European study of breakthrough cancer pain: pain characteristics and patient perceptions of current and potential management strategies. Eur J Pain. 2011;15:756-763.

79. Chou R, Fanciullo GJ, Fine PG, Miaskowski C, Passik SD, Portenoy RK. Opioids for chronic noncancer pain: prediction and identification of aberrant drug-related behaviors: a review of the evidence for an American Pain Society and American Academy of Pain Medicine clinical practice guideline. J Pain. 2009;10:131-146.
80. Moore TM, Jones T, Browder JH, Daffron S, Passik SD. A comparison of common screening methods for predicting aberrant drug-related behavior among patients receiving opioids for chronic pain management. Pain Med. 2009;10:1426-1433.

81. Laulin JP, Maurette P, Corcuff JB, Rivat C, Chauvin M, Simonnet G. The role of ketamine in preventing fentanyl-induced hyperalgesia and subsequent acute morphine tolerance. Anesth Analg. 2002;94:1263-1269, table of contents.

\section{Publish your work in this journal}

The Journal of Pain Research is an international, peer-reviewed, open access, online journal that welcomes laboratory and clinical findings in the fields of pain research and the prevention and management of pain. Original research, reviews, symposium reports, hypothesis formation and commentaries are all considered for publication.

\section{Dovepress}

The manuscript management system is completely online and includes a very quick and fair peer-review system, which is all easy to use. Visit http://www.dovepress.com/testimonials.php to read real quotes from published authors. 